\title{
Aprendizagem além do espaço escolar: uma experiência educativa em atividades de extensão na educação tecnológica
}

\author{
Carlos Emilio Padilla Severo, Rodrigo Figueira de Freitas, Tainã Milano, Márcio \\ Spenst, Alex Sandro Ernandes Valério
}

Departamento de Ensino, Pesquisa e Extensão (DEPEX) - Instituto Federal Sul-riograndense (IFSul) - Av. Leonel de Moura Brizola, 2501 - 96.418-400 - Bagé - RS

\{carlossevero, marciospenst, alexvalerio\}@ifsul.edu.br, \{foolha, tainamilano\}@gmail.com

\begin{abstract}
This paper describes the results of an educational practice within the context of an extension program realized in partnership between the Instituto Federal Sul-rio-grandense (IFSul) and the fundamental school Dr. João Severiano da Fonseca. The educational practice involved a case study about the influence of extension projects in the education and learning of students of technical education. The results show the positive aspects of practical and professional experience of the students.
\end{abstract}

Resumo. O presente artigo descreve os resultados de uma prática educativa no âmbito de um projeto de extensão realizado em parceria entre o Instituto Federal Sul-rio-grandense (IFSul) e a Escola Municipal de Ensino Fundamental Dr. João Severiano da Fonseca. A prática educativa envolveu um estudo de caso acerca da influência de projetos de extensão na formação e aprendizagem de estudantes do ensino tecnológico. Os resultados demonstram os aspectos positivos da vivência prático-profissional dos estudantes.

\section{Introdução}

O espaço e tempo destinados às atividades de ensino no ambiente escolar nem sempre são suficientes para o desenvolvimento de uma interação entre professor e aluno que proporcione oportunidade de aprendizagem. De acordo com Souza et al (2010), a maior parte do tempo de uma aula é gasto com a exposição de conteúdo do professor, pouco tempo é destinado à mediação. O limite de tempo imposto pelas aulas delimita a ação docente em suas intervenções pedagógicas. Aliado a isso, temos também a segmentação de conteúdos entre diversas disciplinas que dividem fatias de tempo ao longo do período letivo. Neste sentido, faz-se necessária a ampliação do espaço de aprendizagem, onde o estudante possa vivenciar os conceitos abordados nas disciplinas na forma de abordagens práticas e interdisciplinares.

Dessa forma, concordamos com Pacheco (2010), que afirma que a educação não ocorre apenas nos espaços de educação formal. Ela resulta das experiências vivenciadas em todos os espaços da sociedade. O que nos levou a refletir sobre alternativas de ampliação do espaço/tempo de aprendizagem dos estudantes e propor um projeto de 
V Congresso Brasileiro de Informática na Educação (CBIE 2016)

Anais do XXII Workshop de Informática na Escola (WIE 2016)

extensão junto a comunidade. Neste sentido, surgiu a demanda de desenvolvimento de um sistema de gestão de conteúdos proposto pela Escola Municipal de Ensino Fundamental Dr. João Severiano da Fonseca, localizada no município de Bagé. A escola conta com aproximadamente 600 alunos matriculados nas seguintes modalidades: Educação Infantil, Ensino Fundamental e Educação de Jovens e Adultos (EJA).

A escola emprega como filosofia a construção de um espaço onde saberes estejam voltados para a aprendizagem do aluno e sua formação como cidadão autônomo, crítico e participativo, capaz de atuar com competência, dignidade e responsabilidade na sociedade que vive. Cujo objetivo é proporcionar ao educando um ambiente acolhedor para o bom andamento do processo ensino e aprendizagem de forma interdisciplinar, crítica, organizada, criativa, dinâmica, visando uma educação conscientizadora e participativa.

Desta maneira, o projeto propôs um trabalho colaborativo envolvendo a elaboração de um sistema de informação para gerenciamento de conteúdo online para escola parceira. Tal tecnologia visou proporcionar um espaço virtual para aproximação da comunidade escolar, envolvendo gestores, professores, servidores, estudantes e pais. A ideia foi pautada na concepção de uma tecnologia para gestão do conteúdo de interesse da comunidade escolar, para que estudantes, pais e servidores da instituição parceira pudessem acompanhar e colaborar com as atividades desenvolvidas na escola.

O objetivo geral do trabalho foi possibilitar uma alternativa às aulas teóricopráticas curriculares do curso superior de Tecnologia em Análise e Desenvolvimento de Sistemas, na forma de realização de uma prática interdisciplinar envolvendo atividades que os estudantes irão encontrar no decorrer de suas profissões. Tais como: especificação conceitual de software e programação de aplicações. Dessa forma, proporcionando não só o desenvolvimento dos conceitos teóricos ao longo das disciplinas, mas também, permitir ao estudante experimentar atividades profissionais ainda no interior da instituição durante sua formação acadêmica.

Com o delineamento do objetivo geral do trabalho, levantamos os seguintes objetivos específicos, os quais auxiliaram na definição das ações que foram desenvolvidas ao longo do projeto: permitir aos estudantes a interação com metodologias empregadas na área de desenvolvimento de software; possibilitar que os estudantes pudessem ter uma vivência prática com processos e ferramentas para construção de software; despertar no estudante a importância do trabalho em equipe e das relações humanas em suas atividades profissionais; e, ampliar possibilidades de aprendizagem dos estudantes através de vivências práticas.

No que tange ao aspecto participação da comunidade escolar, com auxílio do representante da instituição parceira, levantou-se a seguinte problemática: de que forma uma tecnologia de software poderia auxiliar na concepção de uma ferramenta online visando a aproximação da comunidade escolar?

Sendo assim, alinhado aos princípios norteadores da missão da instituição parceira, propomos o projeto de construção do sistema de gestão de conteúdos para escola. Para isso, foram adotados princípios de análise e desenvolvimento de sistemas de informação. Desde o levantamento de requisitos até a implantação da aplicação. Neste sentido, a equipe envolvida no projeto buscou apoio na literatura técnica para embasamento teórico do projeto de extensão. Portanto, descrevemos os aspectos que 
V Congresso Brasileiro de Informática na Educação (CBIE 2016)

Anais do XXII Workshop de Informática na Escola (WIE 2016)

fundamentaram o trabalho nas próximas sessões.

\section{Projetos de extensão, aprendizagem e desenvolvimento de software}

Os projetos de extensão podem ser um espaço de oportunidade de aprendizagem. Em tais espaços podem ser vivenciadas práticas educativas, bem como, práticas profissionais que o estudante irá encontrar no momento de sua inserção no mundo do trabalho.

De acordo com Santos (2012), a atuação no mundo do trabalho exige do profissional um perfil onde o mesmo seja o agente de intervenção no domínio teórico, crítico e reflexivo ao longo do processo histórico de construção da realidade social onde está inserido. A extensão permite ao estudante articular os conhecimentos teóricos com os operacionais inerentes de sua atividade. Além disso, cria oportunidades para o desenvolvimento do trabalho em equipe (COSTA et al, 2011).

Para Santos (2012) a extensão é um importante espaço para práticas sociais e profissionais. Tal espaço possibilita a integração entre dimensões investigativas e interventivas, propiciando aos estudantes uma sólida e significativa aprendizagem profissional. Isso permite a ampliação de horizontes a partir da integração entre o meio acadêmico e a sociedade. Trata-se de uma dimensão importante na relação entre teoria e prática, promovendo a troca de saberes no meio acadêmico e sociedade.

Conforme Raabe et al (2007), os projetos de extensão exercem uma função importante, pois permitem a socialização do conhecimento desenvolvido ao longo do curso. Bem como, permite a retro-alimentação para atividades de pesquisa envolvendo a comunidade e os processos educativos. Os autores destacam que atividades de extensão ampliam a formação do estudante, tornando-o engajado social e tecnicamente. Bem como, preparando-o para interagir em suas atividades profissionais.

Sendo assim, propomos um projeto de extensão visando exatamente a possibilidade de ampliação do espaço e tempo de aprendizagem do estudante do curso de Tecnologia em Análise e Desenvolvimento de Sistemas. Além disso, buscamos parceria com uma escola municipal visando a integração e troca de conhecimentos entre a comunidade local e a instituição. Para isso, foi desenvolvido o sistema de gestão de conteúdos da escola onde os estudantes puderam vivenciar a prática de um processo de desenvolvimento de software, aliando os conceitos abordados em diversas disciplinas do curso com a prática profissional.

De acordo com Sommerville (2007) o processo de desenvolvimento de uma aplicação de software inicia no levantamento de requisitos, passando por uma série de etapas primordiais para concepção de uma aplicação de qualidade. Wazlawick (2013), complementa informando que a documentação das etapas auxiliam na sincronização da equipe de trabalho, norteando e organizando o processo de software. Neste sentido, foi adotada a UML (Unified Modeling Language) como tecnologia de referência na construção de modelos em todas as etapas do processo. Guedes (2009) explana que a UML é uma linguagem padronizada, a qual auxilia na construção de modelos que permitem a comunicação entre os componentes da equipe de trabalho durante a construção de uma aplicação de software.

Além disso, o projeto envolveu a pesquisa, estudo e definição de uma tecnologia de gestão de conteúdos (Content Management System - CMS) para construção de uma aplicação. De acordo com Tori (2010), um CMS é uma ferramenta de apoio a criação, edição e gerenciamento de conteúdo de sites, facilitando o processo de manutenção do 
V Congresso Brasileiro de Informática na Educação (CBIE 2016)

Anais do XXII Workshop de Informática na Escola (WIE 2016)

conteúdo, abstraindo a etapa de codificação do software. Com a utilização de uma série de funcionalidades suportadas por um CMS, as dificuldades geralmente encontradas na definição e elaboração do site são atenuadas, permitindo ao desenvolvedor a concentração na estrutura do conteúdo em si.

Para concepção do software foi adotada a linguagem de programação Java. Segundo Schildt et al (2013), trata-se de uma tecnologia madura e apropriada para construção de aplicações para Web. Visto que o foco foi a construção de um sistema de gestão de conteúdos online para escola, preferimos adotar a tecnologia Java para isso.

\section{Abordagem metodológica da prática educativa}

A proposta envolveu a participação de um estudante bolsista e outro voluntário, ambos vinculados ao curso superior de Tecnologia em Análise e Desenvolvimento de Sistemas do Instituto Federal Sul-rio-grandense (IFSul), campus Bagé. Dessa forma, pretendemos proporcionar aos estudantes participantes do projeto um espaço de aprendizagem além da sala de aula e ambiente escolar, envolvendo práticas educativas e vivências relacionadas a profissão do Tecnólogo em Análise e Desenvolvimento de Sistemas. Cabe ressaltar, que o trabalho foi interdisciplinar, pois envolveu três professores de disciplinas distintas, mas inter-relacionadas da área de Informática do campus. Cujos conteúdos abordados ao longo do semestre convergiram na aplicação deste projeto. As disciplinas envolvidas foram Modelagem de Sistemas de Informação, Banco de Dados e Programação para Internet.

No aspecto metodológico, o trabalho realizou uma pesquisa de desenvolvimento tecnológico, com base em um estudo de caso envolvendo a análise e levantamento de requisitos, bem como, a elaboração de uma aplicação de software a qual visou proporcionar um espaço de trocas e convivência entre os membros da comunidade escolar. Para isso, o projeto foi desenvolvido de acordo com as seguintes etapas:

$\mathbf{1}^{\text {a }}$ Etapa: definição da equipe de trabalho. A equipe executora foi constituída de um coordenador, dois professores colaboradores do próprio IFSul e um professor colaborador externo, ligado a instituição parceira que gerou a demanda do projeto. Para complementar a equipe de trabalho foi realizada a seleção do estudante bolsista e voluntário que atuaram no projeto.

$2^{\text {a }}$ Etapa: análise dos requisitos da aplicação e definição das funções desejadas do software. Esta etapa foi desenvolvida com colaboração dos docentes envolvidos no projeto de extensão. Um conjunto de documentos do software foi o produto resultante desta etapa. Tais como: diagramas de casos de uso e diagramas de classes. Os documentos foram produzidos pelos estudantes participantes do projeto.

$3^{\text {a }}$ Etapa: definição de tecnologias empregadas no processo de especificação e construção da aplicação. Nesta etapa, foram analisadas as potencialidades e limitações de tecnologias na concepção do software. Toda equipe foi envolvida nesta etapa.

$4^{\text {a }}$ Etapa: prototipação da aplicação, testes e validação junto a instituição parceira. Nesta etapa, os docentes atuantes no projeto, junto com os estudantes, construíram um protótipo do software.

$5^{\text {a }}$ Etapa: implantação da aplicação. Nesta etapa foi definido um servidor de hospedagem para implantação da aplicação. O acompanhamento técnico do processo foi 
V Congresso Brasileiro de Informática na Educação (CBIE 2016)

Anais do XXII Workshop de Informática na Escola (WIE 2016)

realizado pela equipe executora.

$6^{\text {a }}$ Etapa: treinamento da comunidade escolar.

As ações elencadas nas etapas do projeto foram desenvolvidas no período de agosto a dezembro do ano de 2015. Os laboratórios de Informática do IFSul foram utilizados para orientações e desenvolvimento do software pelos estudantes e equipe envolvida no projeto, bem como, para reuniões com a equipe participante.

Como instrumento de coleta de dados foi utilizada a observação participante do orientador durante todo o processo de desenvolvimento do software. Durante cada etapa do processo e no desenvolvimento das atividades elencadas, foram realizadas mediações pedagógicas onde pudemos observar a construção da aprendizagem dos estudantes.

\section{Análise e discussão dos resultados}

A seguir, passamos a descrever os resultados da aplicação do projeto. Neste relato, descrevemos as dificuldades encontradas pela equipe e as aprendizagens desenvolvidas ao longo do processo. Para organizar o relato, dividimos o mesmo em partes, de acordo com cada etapa da metodologia elencada anteriormente.

Na primeira etapa de atividades do projeto foi realizada a definição da equipe de trabalho. O docente externo, vinculado à escola parceira, foi coautor do projeto, visto que foi a escola parceira que gerou a demanda. Os estudantes envolvidos no projeto foram selecionados por edital, cujos requisitos foram: desempenho escolar $\mathrm{e}$ disponibilidade para participação nas atividades. Para compor a equipe de orientadores, foram convidados mais dois docentes para auxiliarem na orientação do desenvolvimento do software na forma de colaboradores. Visto que envolveu uma integração interdisciplinar entre subáreas da Informática, tais como: análise e modelagem, programação, definição do banco de dados e tecnologias envolvidas na elaboração do software.

A integração destas subáreas permitiu aos estudantes participantes do projeto terem uma visão holística sobre o processo de desenvolvimento de um sistema de informação. Esta foi uma das vantagens da proposta deste trabalho. Dado que, muitas vezes, no decorrer das atividades curriculares desenvolvidas em cada disciplina ao longo dos semestres do curso, não é possível esta integração. Neste sentido, corroborando com o que diz Sommervile (2007), que a construção de uma aplicação de qualidade envolve uma série de fases primordiais.

A segunda etapa do trabalho envolveu a análise dos requisitos do software. Entende-se por análise de requisitos a identificação das principais funções desejadas do software, ou seja, o objetivo do software. O que o mesmo irá realizar e de que forma o usuário poderá tirar proveito das funcionalidades providas pela aplicação.

Nesta etapa, houve um envolvimento muito grande da equipe de docentes e o responsável pela instituição parceira. Foram realizadas duas reuniões com o docente da escola para levantamento dos requisitos do software. Esta etapa permitiu muita aprendizagem dos estudantes envolvidos, pois puderam vivenciar como ocorre na prática o levantamento de requisitos, através de entrevistas e apontamentos de funcionalidades desejadas de um software. Ao final da etapa, os estudantes puderam comprovar o que se referia Wazlawick (2013), sobre a importância da documentação do software (diagramas 
V Congresso Brasileiro de Informática na Educação (CBIE 2016)

Anais do XXII Workshop de Informática na Escola (WIE 2016)

elaborados) na sincronização da equipe de trabalho. Esta vivência nos surpreendeu muito, pela maturidade desenvolvida pelos estudantes ao longo do processo.

$\mathrm{Na}$ terceira etapa do trabalho foram definidas as tecnologias empregadas na elaboração dos documentos de requisitos do software. Também foram definidas tecnologias empregadas na programação do sistema de gestão de conteúdos. Utilizamos para isso ferramentas para modelagem de diagramas. Esta foi outra etapa muito valiosa para aprendizagem dos estudantes, pois puderam visualizar e sentir as dificuldades encontradas por uma equipe de desenvolvimento de software. Dificuldades como transcrição do texto de requisitos em diagramas que representam o domínio de funções do software. Os estudantes aprenderam muito e aplicaram os conceitos abordados nas disciplinas do curso. A principal dificuldade encontrada nesta etapa foi a tradução da entrevista que levantou a descrição textual dos requisitos do sistema em diversos diagramas que constituíram a documentação do processo de desenvolvimento de software.

A terceira etapa permitiu que os alunos evidenciassem a constatação de Guedes (2009), quanto a importância e utilidade da linguagem UML na descrição dos modelos do sistema de informação. Isso, deve-se ao fato de que a linguagem possui construções apropriadas para descrição de cada fase de desenvolvimento de uma aplicação de software. Permitindo, até mesmo, a previsão de uma arquitetura do software proposto. Isso ficou evidente para os estudantes os quais opinaram e realizaram reflexões sobre o melhor modelo de software a ser empregado. Esta foi uma experiência muito gratificante tanto para os estudantes como para a equipe de orientadores envolvida, visto que os estudantes puderam compreender a finalidade dos diagramas durante a especificação conceitual do software.

A quarta etapa do projeto envolveu a construção (programação) do software com a tecnologia escolhida. Em posse dos documentos de requisitos do software e de acordo com a arquitetura definida na etapa anterior, foi iniciado o processo de codificação da aplicação. Gostaríamos de destacar nossa satisfação com o desempenho dos estudantes no decorrer desta etapa. Esta foi a etapa onde pudemos observar a contribuição que um projeto de extensão como este pode oferecer para aprendizagem dos estudantes. A área de desenvolvimento de software costuma ser muito complexa, visto que envolve aspectos relacionados à lógica, bem como, dificuldades encontradas pela própria linguagem de programação empregada. Isso ocorre dada a grande carga de abstração envolvida. Realmente, não é fácil para estudantes enfrentarem as dificuldades impostas pelo processo de codificação de um software. Entretanto, os estudantes participantes do projeto foram muito bem nesta etapa. Trabalharam com muita dedicação na elaboração do sistema de gestão de conteúdos para escola.

Durante a programação do sistema os estudantes puderam entender na prática os conceitos abordados por Schildt et al (2013), tais como: abstração, herança e modularização no processo de programação de aplicações de software. Esta etapa proporcionou uma aprendizagem rica em diversos aspectos relacionados a construção de programas.

A partir da quinta etapa surgiram as principais dificuldades encontradas ao longo do trabalho. Dificuldades não relacionadas diretamente a aprendizagem dos estudantes. Nem mesmo relacionadas a prática de orientação dos docentes. Mas sim, relacionadas a falta de recursos financeiros do projeto. Visto que o projeto não foi contemplado com recursos financeiros, não foi possível a contratação de um serviço de hospedagem. Como 
V Congresso Brasileiro de Informática na Educação (CBIE 2016)

Anais do XXII Workshop de Informática na Escola (WIE 2016)

não existe um serviço gratuito de hospedagem, mesmo para fins educacionais, torna-se necessária a locação de um provedor de serviços de Internet. Neste sentido, a grande frustração da equipe foi a impossibilidade de implantar a aplicação e torná-la disponível online através da Internet. Após a conclusão do software o mesmo foi implantando em um servidor local. O que torna o mesmo acessível à comunidade, mas somente a partir de computadores da rede interna da instituição.

\section{Reflexões conclusivas}

Iniciamos realizando uma reflexão sobre o objetivo geral proposto no projeto. Portanto, compreendemos que a proposta inicial de proporcionar uma oportunidade de ampliar o espaço de aprendizagem do estudante, não nos limitando somente aos planejamentos previstos nos componentes curriculares do curso, foi plenamente atingida. Isso pode ser constatado através do relato onde descrevemos o envolvimento dos estudantes em todas as fases propostas no projeto. Os benefícios de uma prática de desenvolvimento de software, orientada por uma equipe interdisciplinar de professores de um curso de tecnologia, pode gerar efeitos positivos no desenvolvimento da aprendizagem dos estudantes. A definição e execução de um trabalho interdisciplinar amplia a compreensão e uma visão macro do processo de desenvolvimento de software. O que, muitas vezes, não é possível quando trabalhamos os componentes curriculares de forma isolada. Sem que ocorra uma inter-relação entre os conteúdos abordados nas disciplinas de um curso.

Outro aspecto observado que permite uma reflexão é a interação constante dos estudantes com tecnologias empregadas no mundo do trabalho. Principalmente, tecnologias que os estudantes abordam durante seus estudos no curso e que são amplamente empregadas na construção de software. Tal aspecto nos deixa muito satisfeitos com o trabalho desenvolvido pelo corpo docente do nosso campus. Visto que tanto conceitos como as abordagens práticas, ferramentas e metodologias empregadas no ensino dos componentes curriculares, estão alinhados ao que o mundo do trabalho demanda.

Cabe destacar, que a proposta evidenciou aos estudantes a importância do desenvolvimento de um trabalho em equipe multidisciplinar. As relações humanas e sua importância para o sucesso de qualquer tipo de empreendimento. O desenvolvimento de maturidade dos estudantes ao longo do processo foi marcante. Muita aprendizagem foi desenvolvida no âmbito das relações profissionais e humanas ao longo do processo.

Para finalizar, gostaríamos de sugerir alguns desdobramentos possíveis da prática educativa apresentada neste artigo. Um primeiro trabalho futuro seria a ampliação do projeto para atender outras demandas da instituição parceira, tal como a elaboração de um sistema de controle acadêmico. Outro desdobramento possível seria a apresentação de um novo projeto que busque recursos financeiros para que a aplicação possa ser implantada em um serviço de hospedagem. Com isso, seria viável criar novas possibilidades de ampliação de espaços de aprendizagem. Onde docentes, estudantes e servidores da escola poderiam trabalhar de forma colaborativa e construir seus próprios recursos educacionais. 
V Congresso Brasileiro de Informática na Educação (CBIE 2016)

Anais do XXII Workshop de Informática na Escola (WIE 2016)

\section{Referências bibliográficas}

COSTA, A.; SILVA, P. B. (2011). Extensão universitária brasileira: possibilidades, limitações e desafios. São Paulo: Nelpa.

GUEDES, G. (2009). UML 2: Uma abordagem prática. 1ª Edição. São Paulo: Novatec.

PACHECO, E. (2010). Os Institutos Federais: uma revolução na educação profissional e tecnológica. Brasília: MEC/SETEC.

RAABE, A. L. A.; ALVES, G. A.; PEDRO, C. R.; CERCAL, J. J. (2007). Oficinas de utilização de Software Educacional: Um relato de experiência. In: Anais do Workshop de Informática na Escola.

SANTOS, M. P. (2012). Extensão universitária: espaço de aprendizagem profissional e suas relações com o ensino e a pesquisa na educação superior. Revista Conexão UEPG, v. 8, n. 2, p. 154-163.

SCHILDT, H.; SKRIEN, D. (2013). Programação com Java: uma introdução abrangente. Porto Alegre: Bookman.

SOUZA, F. N.; Moreira, A. (2010). Perfis de questionamento em contextos de aprendizagem online. IE Comunicaciones: Revista Iberoamericana de Informática Educativa, n. 12, p. 15-25.

SOMMERVILLE, I. (2007). Engenharia de Software. $8^{\text {a }}$ Edição. São Paulo: Pearson.

TORI, R. (2010). Educação sem distância: as tecnologias interativas na redução de distância em ensino e aprendizagem. São Paulo: Editora Senac.

WAZLAWICK, R. S. (2013). Engenharia de Software: conceitos e práticas. Rio de Janeiro: Campus. 